\title{
Heating of the Natural Gas at the Gas-distributive Installation
}

\author{
Olena Savchenko, Ivan Balins’kyi, Grygoriy Shpak \\ National University "Lviv Polytechnic" \\ Institute of Building and Environmental Engineering, Chair "Heat, Gas supply and ventilation" \\ e-mail: orest.voznyak@i.ua
}

\begin{abstract}
Heating of natural gas on the gas-distributive installations is carried out for prevention of creation of gas hydrates in gas pressure controller. There are a few methods of heating of natural gas: complete heating of gas and heating of gas pressure controller. The indicated methods have a row of failings, the delivered from which is possible at the use of vortex tube. Work of vortex tube consists of the simultaneous making of two streams: heated and frappe. The heated stream is used for a serve on a gas pressure controller which shuts out it freezing. Little price, insignificant sizes, absence of motive details helps to use a vortex tube for heating of natural gas on the gasdistributive installations.
\end{abstract}

Key words: gas-distributive installations, gas pressure controller, heating of natural gas, vortex tube, heated stream.

\section{Introduction}

One of the basic structures gas transport systems is natural gas-distributive installations, in which high pressure gas of main pipeline gets lower to medium or low pressure gas in distribution pipelines. Gas decompression (throttling) occurs in gas pressure controller. When throttling gas pressure and temperature decreases, moisture gas varies. This so-called JouleThomson choke-effect. This phenomenon can lead to the formation of the gas hydrates on the moving parts of the pressure controller. The gas hydrates worsens the process of regulation of natural gas. Freezing of controller valve spool to the saddle can be. This can lead to disruption of the gas transport system.

Objective of the work. The safe, compact and economical method of natural gas heating before throttling process at gas-distributive installations work out. 


\section{Results of investigations}

The natural gas heated to prevent the formation of crystalline hydrates. Depending on the performance of gas-distributive installations general heating of natural gas and local heating of the pressure regulator body are differed.

The general heating of natural gas is used when productivity gas-distributive installations less than $70000 \mathrm{~m}^{3}$ /hour. Gas is heated in heaters various types. Heaters differ by the type of coolant (hot water, electric energy, water vapor) and location heat transfer surface (exchangers "pipe in pipe", pipe-casing). [1]

For example in Germany [2], in the gas-distributive installations since 1993 are used doublepipe heat exchangers of gas production company "GEA Renzmann \& Grünewald". Thermal power of heater $400 \mathrm{~kW}$. They have the following advantages: high efficiency $(80-90 \%)$, precise temperature control gas output from the GDS, the small heat losses to the environment, work in the absence of power from the network for 4 hours a day, closed heating system, no corrosion in it, the protection of heating system of gas stream into it, prevention leakage of gas from leaks of heat exchanger, opportunity of connect the premises to household heating systems. Construction of the heater is presented in Figure 1.

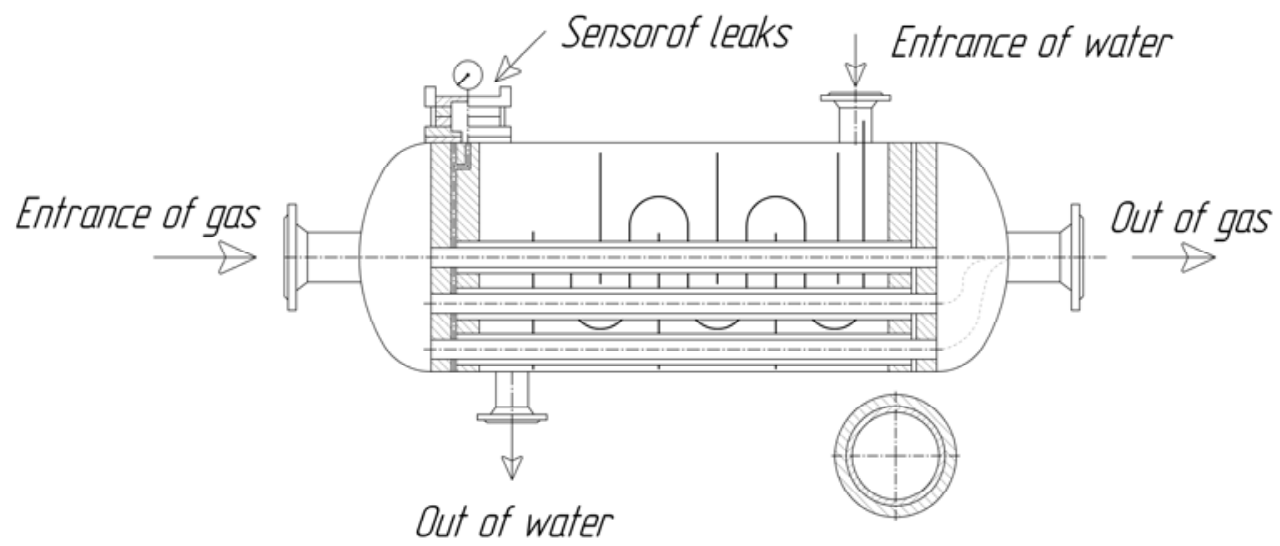

Figure 1: Double-pipe heat exchanger of "GEA Renzmann \& Grünewald”.

Using the general heating of natural gas has some disadvantages: requiring additional fuel gas and specially built premises, have large size and mass, and therefore require high investment and material costs of their accommodation and service, some heaters dangerous to use.

The local heating of the pressure regulator was used, albeit rarely, even in the 60's and 70's. [3] It is used when productivity gas-distributive installations more than $70000 \mathrm{~m}^{3} /$ hour. A typical construction of such heating is presented in [10] and is showed in Fig. 2.

The body of the controller in this case is placed in a metal enclosure. The pipe of heating system gas-distributive installations are laid there. The metal enclosure and underwater pipelines are covered by heat-insulation to reduce heat losses to the environment. By means 
of heating of the body controller, temperature of its walls are higher than the dew point temperature of water vapor, so hydrates are not formed.

The local heating of the pressure regulator do not require much heat and large costs of the heating equipment. But there are drawbacks: under the existing scheme gas-distributive installations hard to achieve natural circulation of water in the heating system; gas not heated, which serves to supply targets for pressure regulators, protection system and devices with multistage records option.

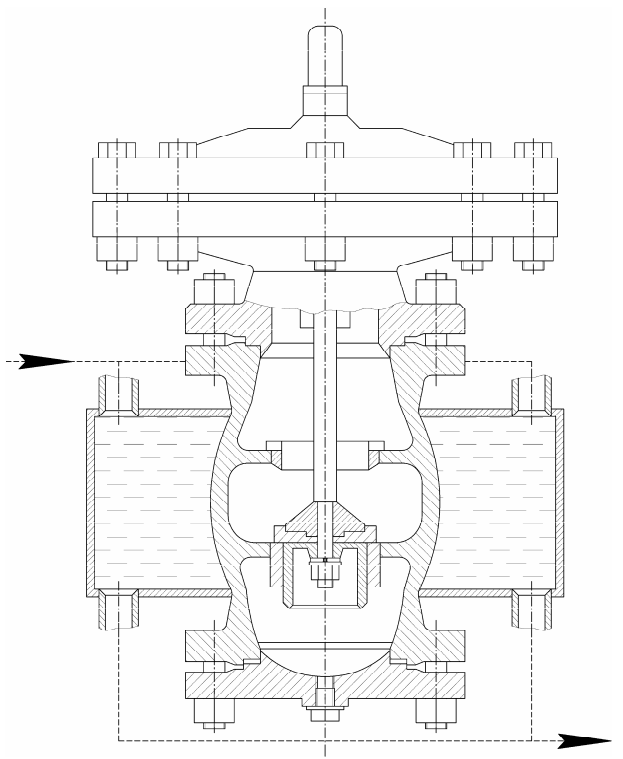

Figure 2: The gas pressure controller of the РД -type with "enclosure".

The most progressive and cost-effective method of heating natural gas before the throttling at gas stations are heating in the vortex tube. This method allows to heat of natural gas to without any kind of energy (including electricity) and moving parts. In addition, vortex tube allow to relieve work pressure regulator gas in the heating period. Use of vortex tube for heating the gas at gas stations with low productivity allow its small size and weight, a short start period, low cost tube and low capital costs.

As recent studies [4], at gas stations with a capacity of up to $2500 \mathrm{~m}^{3} /$ hour for general heating of natural gas can use of vortex tube. Principal scheme of the vortex tube is presented in Figure 3.

The work of the vortex tube is the following [5]. Compressed gas is through the tangential nozzle channel in the tube. There are established an intensive roundabout and an uniform temperature field. Layers of gas near the axis is cooler than the input gas, the peripheral layers of swirling flow is warmer than the input gas. This phenomenon is called the effect of the Ranque. The cold gas stream is given through the diaphragm, heated gas through the throttle valve is goes with the other part of pipe. If you close the throttle gradually, the overall pressure in the vortex tube increases. If the flow of cold stream through the aperture is 
increased, correspondingly expense of hot stream is decreases. Thus the temperature of cold and warm streams also can change.

Experimental research of energetic separator on natural gas high pressure is almost impossible. This is due to the need many experiments to determine the optimum size of the vortex tube, mode changing the gas distribution station, explosion and fire danger of natural gas. It was therefore decided to conduct experimental studies on compressed air. After that enter for the converting experimental data to analytical.

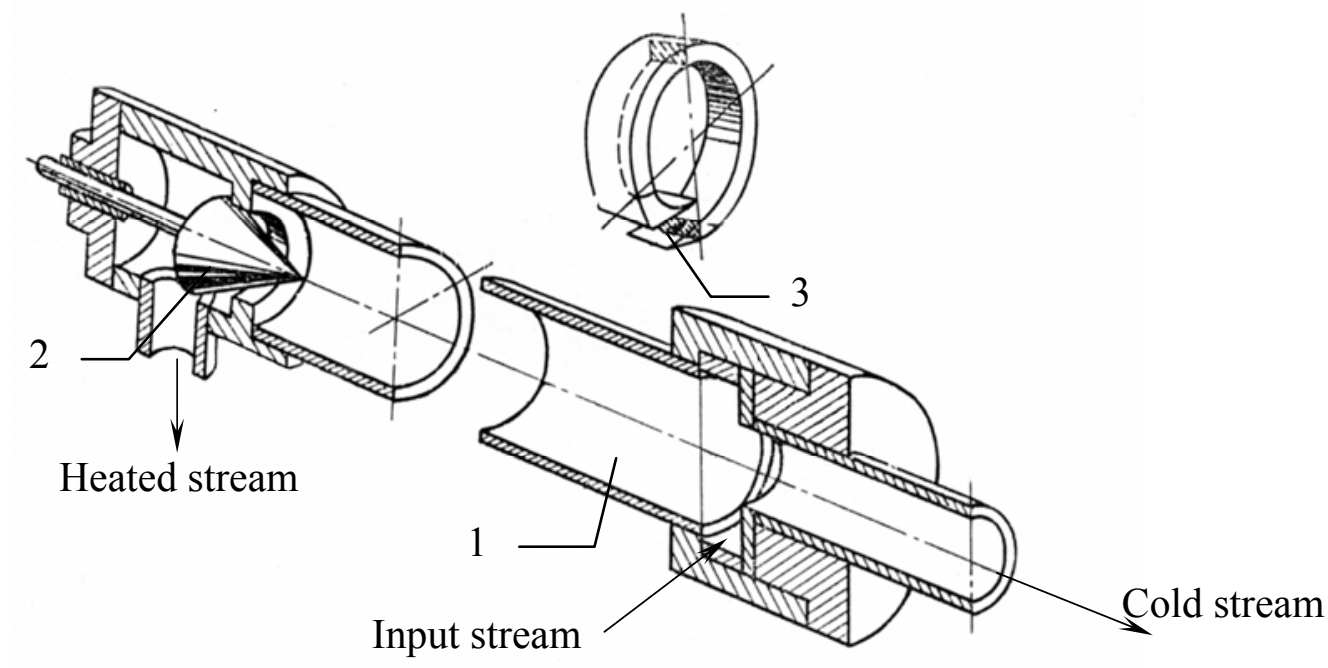

Figure 3: Principal scheme of the vortex tube:

1 - cylindrical tube, 2 - butterfly valves, 3 - tangential input

As the correction factor was proposed coefficient of compliance energetic separation air and natural gas $\alpha$ [6]. It depends on the individual physical properties of gases, particularly Adiabatic index $k$. Adiabatic index of natural gas is defined as the sum of Adiabatic indexs it components.

In our case, for natural gas transported by pipelines, is a mixture of components, including methane, ethane, propane. Then Adiabatic index for a mixture of components is determined by formula

$$
k_{\text {mix }}=0,01 \sum_{i=1}^{n} y_{i} k_{i}
$$

where $n=1,2,3, \ldots$ - number of components in the mixture, $k_{i}, y_{i}$ - respectively dimensionless Adiabatic index and volume fraction, $\%$, of i-component in the mixture.

For natural gas with different components the coefficient $\alpha$ calculated by depending on the composition of gas at the Adiabatic index in the range $1.13-1.31$. Adiabatic index took depending on the composition of natural gas under the law of additivity.

Dimensionless coefficient of compliance approximated by analytical dependence as: 


$$
\alpha=1,79 k-1,48
$$

For known values $\Delta t_{h}^{a i r}, \mathrm{~K}$, of the degree of heating of air coefficient of compliance $\alpha$ for all other similar thermodynamic and geometric parameters of energetic separation can determine the degree of heating, $\mathrm{K}$, for energetic separation of natural gas:

$$
\Delta t_{h}^{\text {gas }}=\alpha \Delta t_{h}^{\text {air }} .
$$

Experimental studies on compressed air have been conducted to establish the optimal sizes of vortex tube and for establishing of dependence the geometrical dimensions on the degree of heating of the air and portion of heated flow.

At experiments were considered such simplification and assumptions: camera energetic separation was cylindrical and adiabatic, tangential nozzle was rectangular, pressure and temperature at the entrance of vortex tube were taken constant.

Prior experimental studies the pre-calculation of vortex tube was conducted for terms of compliance of energetic separation. Orifice nozzle type $f_{n}, \mathrm{~m}^{2}$, was determined with formula:

$$
f_{n}=\frac{G_{i n} \cdot a}{k \cdot \partial_{c r} \cdot \partial_{\text {in }}},
$$

where $G_{\text {in }}$ - second expense of compressed air, $\mathrm{kg} / \mathrm{s}, a$ - the critical speed, $\mathrm{m} / \mathrm{s}$, at absolute temperature the incoming stream $T_{i n}, \mathrm{~K}$, gas constant $R, \mathrm{~kJ} /(\mathrm{kg} \cdot \mathrm{K})$, dimensionless Adiabatic index $k$ :

$$
a=\sqrt{\frac{2 k}{k+1} R} \cdot \sqrt{T_{i n}}
$$

where $p_{c r}$ - critical relative pressure, $\mathrm{Pa}, p_{i n}$ - pressure of input stream, $\mathrm{Pa}$.

During the research was conducted 3-factor experiment, for which the plan chosen orthogonal second order with the following factors:

- relative area $\bar{f}=f_{d} / f_{e}$ - is the ratio of cross-sectional area the diaphragm to the cross-sectional area the entrance;

- relative length $\bar{l}=l_{t} / d_{t}$ - is a ratio length of the camera energetic separation to its diameter;

- share of heat stream $\varepsilon$ - is the ratio expense of heated stream of vortex tube to the expense input stream.

Value factors was varied within: $x_{1}$ - from $\bar{f}=0,5$ to $\bar{f}=1,7 ; x_{2}$ - from $\bar{l}=10$ to $\bar{l}=30$ and $x_{3}$ - from $\varepsilon=0,1$ to $\varepsilon=0,9$.

The experimental results were processed on a computer by means of mathematical statistics with confidence probability 0.95 . The significance of regression coefficients and confidence interval tested using Student's criterion, model adequacy was checked by Fisher's numbers.

Results of experimental studies have been approximated by analytical dependence as: 


$$
\begin{aligned}
& \Delta t_{h}^{a i r}=-5,65+10,47 \bar{f}-4,03 \bar{f}^{2}+\bar{l}\left(0,04-0,01 \bar{f}+0,02 \bar{f}^{2}\right)+ \\
& +\varepsilon\left(40,94-6,88 \bar{f}+2,35 \bar{f}^{2}+\bar{l}\left(-6,39+17,87 \bar{f}-7,13 \bar{f}^{2}\right)\right)+ \\
& +\varepsilon^{2}\left(-45,46+14,21 \bar{f}-4,82 \bar{f}^{2}+\bar{l}\left(6,51-18,25 \bar{f}+7,21 \bar{f}^{2}\right)\right)
\end{aligned}
$$

Optimization of dependence (6) allowed to determine the optimal geometric dimensions of vortex tube and share a heat stream. They are, $\bar{f}=1.27, \bar{l}=20$ and $\varepsilon=0.495$.

To prevent the formation of crystalline hydrates of natural gas temperature of natural gas before the pressure controller should be $5-7 \mathrm{~K}$ higher than the dew point, namely:

$$
t_{\text {p.con. }}=t_{c r}+(5 \div 7) \mathrm{K}
$$

where $t_{p . c o n}$ - temperature of gas before the pressure controller, $\mathrm{K}, t_{c r}$ - critical temperature formation of crystalline hydrates, $\mathrm{K}$,

Vortex tube with optimal dimensions was produced and installed on real gas-distributive installations on the patented scheme. [7] Simplified schematic of the gas-distributive installations with vortex tube on the technological line is shown in Figure 4.

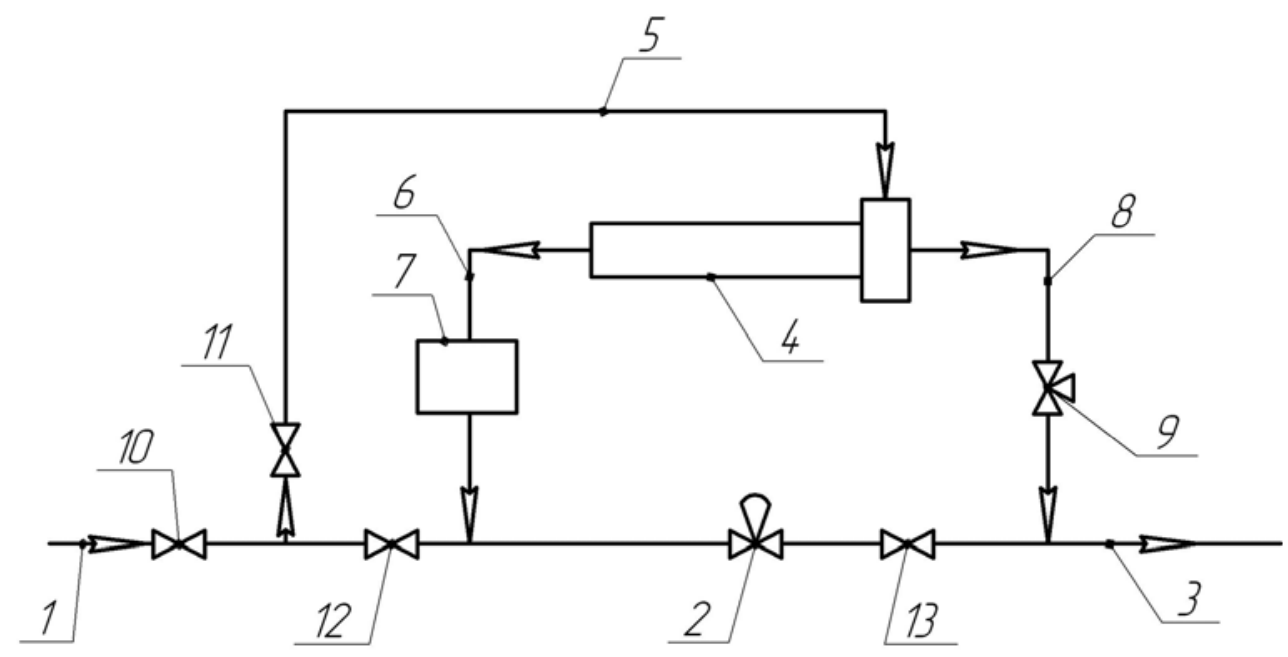

Figure 4: The technological line of the gas-distributive installations with vortex tube.

1 - the main gas pipeline, 2 - gas pressure controller, 3 -distribution gas pipeline,

4 - vortex tube, 5 - pipeline of input gas stream, 6 - pipeline of heat gas stream, 7 - separator, 8 - pipeline of cold gas stream, 9 - protective stop-valve, 10,11,12,13 - taps.

Gas-distributive installations works as follows. Gas from gas mains with pressure 7,5 - $3 \mathrm{MPa}$ through taps 10 and 12 goes in the gas pressure controller, in which the pressure was drop to $1,2-0,1 \mathrm{MPa}$ and automatically was maintained constant regardless of expenses. (The tap 11 is closed.) Then through tap 13 gets to the distribution pipeline 3. 
If the icing threatened by gas pressure controller, you must enable vortex tube 4 . This can happen with increasing consumption natural gas, often in the heating period. The tap 12 closes and opens tap 11. Then the entire flow of gas from main gas pipeline goes to the vortex tube 4 . In the vortex tube the thermal separation of input compressed natural gas was divided for two: heated stream and cold stream. The heat stream by gas pipeline 6 through separator 7 goes to the gas pressure controller 2. The throttling of heat gas is without formation of crystalline hydrates. This is the main objective of heating of natural gas at gas-distributive installations. The cold stream by gas pipeline 8 through protective stop-valve 9 goes to the distribution gas pipeline 3. Protective stop-valve 9 maintains pressure cold flow after vortex tubes at the level of pressure in the distribution gas pipeline 3. Photo vortex tubes at the real gas-distributive installation is shown in Fig. 5.

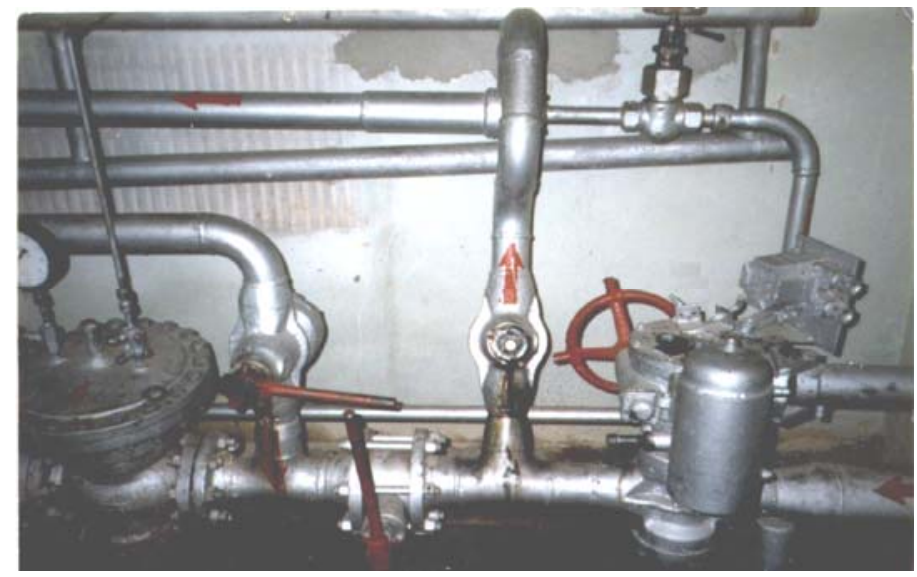

Figure 5: The vortex tube at the real gas-distributive installation.

During the period of observation on the work of vortex tube at the real gas-distributive installation the icing pressure controller was not observed. The results of the work of vortex tube during the heating season by month are shown in Figure 6.

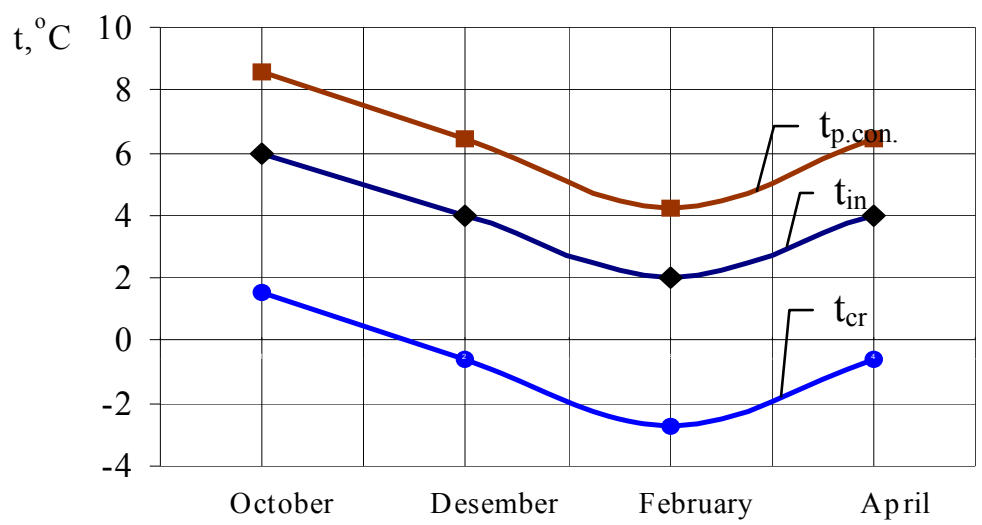

Figure 6: Temperature mode of vortex tube on the real gas-distributive installation:

$t_{c r}$ - critical temperature formation of crystalline hydrates,

$t_{\text {in }}$ - temperature of the natural gas at the entrance of gas-distributive installation, $t_{\text {p.con. }}$ - temperature of natural gas before the pressure controller. 
As shown in Figure 6, during the heating period the temperature of natural gas before the pressure controller $t_{p . c o n}$. was higher than the critical temperature formation of crystalline hydrates $t_{c r}$.

Calculation of economic efficiency of using of vortex tube was done by comparing the two options. For basic variant using of a typical gas heater - exchanger ПГ-10 was accepted.

Replacing a typical heat exchanger to energy separator allows, first, prevent the formation of crystalline hydrates in elements of gas pressure controller, second, get rid of fuel gas and electricity, and thirdly to reduce capital and operating costs. All this contributes to reliability of gas supply distribution system.

Reduced costs for fuel gas, additional heat sources and a typical heater of natural gas (including pay-back period) determines the economic efficiency of vortex tube use on gasdistributive installation for heating of natural gas. Economic effect from using of vortex tube for heating of the natural gas at the distribution station is defined as the difference of reduced costs and is 170 thousands UAH/year (prices 2007).

\section{Conclusion}

A safe, compact and economic method of gas heating before throttling at gas-distributive installation stations was submitted.

\section{References}

[1] DUBINSKIY,N.M. (1971). Avtomatizasia gazoraspredelitelnich stansiy.Obzor zarubegnoy literaturi - M.: VNIIOEG.

[2] RUDNIC, A. A. (2003). Ekspluataciya i technichne obslugovuvannya gazorozpodilnich stanciy magistralnich gazoprovodiv: Dovidnic. Rostok. Rudnic A. A., Kolomeev V. M., Rozgonyuc V.V., Grigil M. A. ta in. - K

[3] CHAYCIN, G. A. (1971). Ekspluataciya gazoraspredelitelnich stansiy magistralnich gazoprovodov. - M. Nedra.

[4] KOVAL, R., BANACHEVICH, YU., BALINS'KYI, I.. (1997). Energetichnyi rozpodilyuvach prirodnogo gazu. Zbirnic tez dopovidey: 2-a Mignarodna naukovo-practichna conferenciya $z$ upravlinnya energovicoristannyam. Lviv.

[5] MARTINOV, A. V., BRODYANSKIY, V.M. (1976). Chto takoye vichrevaya truba? Energiya.

[6] KASHINA,O., BALINS'KYI, I. (2001). Efectivnist energetychnogo rozdilennya stisnutich prirodnogo gazu I povitrya. Visnic NU "Lvivska politechnika" "Teploenergetica. Ingeneriya dovcillya. Avtomatizacia.” №432. - S.106 - 109.

[7] BALINS'KYI,I., KOVAL, R., BANACHEVICH,YU., KASHINA,O. (2001). Patent Ukrainy na vinachid №43673A. Gazorozpodilna stanciya. Byul. №11. 